\title{
Treatment Satisfaction Among Clients Enrolled in Methadone Maintenance Treatment (MMT) Program in Myanmar: A Cross-sectional Study
}

Sun Tun ( $\nabla$ suntun1@gmail.com )

Myanmar Medical Association https://orcid.org/0000-0003-0973-4791

B. Vicknasingam

Universiti Sains Malaysia Centre for Drug Research

Darshan Singh

Universiti Sains Malaysia Centre for Drug Research

\section{Research}

Keywords: methadone, Verona Service Satisfaction Scale, Treatment satisfaction, Myanmar

Posted Date: July 30th, 2021

DOl: https://doi.org/10.21203/rs.3.rs-742094/v1

License: (c) (1) This work is licensed under a Creative Commons Attribution 4.0 International License.

Read Full License 


\section{Abstract}

\section{Background}

To address the long-standing opioid abuse problem, Myanmar has established the methadone maintenance treatment (MMT) program in 2006. This study aims to determine client's treatment satisfaction towards MMT program in Myanmar.

\section{Method}

A total of 210 clients who have registered in MMT program with a minimum of six-month treatment history were recruited for this cross-sectional study across Myanmar. The Verona Service Satisfaction Scale for Methadone-Treatment (VSSS-MT) was administered to objectively measure methadone treatment satisfaction.

\section{Result}

The majority $(89 \%, \mathrm{n}=186)$ were satisfied with the current methadone treatment program. Specifically, $89.5 \%(n=187)$ claimed to be highly satisfied with the clinic staff professional skills (e.g. doctor, nurse, etc.), $(91.9 \%, n=192)$ satisfied with the basic interventions (instruction between visits, side-effects etc.), and $(74.6 \%, n=156)$ satisfied with specific interventions (e.g. individual rehabilitation and psychotherapy, group therapy etc.) categories. Among the different characteristics of the respondents, higher quality of life on physical, psychological, social and environmental categories, respondents who satisfied on current marital status and current leisure status, respondents who were on alcohol were associated with higher treatment satisfaction on methadone $(p<0.05)$. The result of stepwise binary logistic regression showed alcohol use and physical health had significantly association with treatment satisfaction.

\section{Conclusion}

Despite the high methadone treatment satisfaction, treatment providers must make an attempt to address service limitations in order to maintain clients' participation in MMT program especially for specific intervention categories (e.g. individual rehabilitation and psychotherapy, group therapy etc).

\section{Background}

Global Health Observatory data from the World Health Organization (WHO) mentioned in 2014 that 50\% of the 152 responding countries have methadone available for maintenance treatment of opioid dependence. Meanwhile, $45 \%$ of the 147 responding countries have methadone available for detoxification treatment of opioid dependence (methadone 2014).

World Drug Report 2020 estimated that 57.8 million are opioid users in 2018 around the world and losing $80 \%$ of 42 million years of "healthy life lost" by the implication due to opioid drug use. Drug dependence is mentioned as multi-factorial health disorder with relapsing and remitting in nature. Myanmar is still 
accounting for $7 \%$ of the world's total opium production (UNODC 2020). So, comprehensive intervention packages for harm reduction interventions were also addressed in Myanmar. Methadone programme started and enrolled 260 patients in 2006 in Myanmar according to the report of Drug Dependency Treatment and Research Unit (DDTRU 2015). Since then, 19,991 People who inject drugs (PWID) were treated with methadone for opioid substitution in 2019, which is $21 \%$ of estimated 93,000 PWIDs (T. G. Myanmar 2020). Meanwhile, harm reduction works were being advocated to the administrative and legislative community for desensitization of drug uses alongside the expansion of opioid substitution therapy by the National Drug Abuse Prevention and Control Programme. However, it is important to identify the service satisfactory of the methadone programme to assess the performance of the service delivery, clients' experience on each components of services and types of services they received. The identification of satisfaction can be useful in retaining of the clients in the methadone programme and future planning of quality service expansion after identifying service gaps.

Methadone treatment is effective and associated with the less opioid use ( $\mathrm{Yl}$, et al. 2016) and improved the quality of life of the patients at 6 months after treatment among Malaysian patients (Fei, et al. 2016), as well as 6 month and 12 month follow up among Taiwan patients (Chou, et al. 2013). The methadone program were expanded in China and South East Asia countries like Myanmar and Malaysia after 2000, understanding methadone treatment satisfaction becomes vital to treatment providers. Several validated tools have been designed to assess client's treatment satisfaction. Among the commonly used tools include Client Satisfaction Questionnaire (CSQ-8) (Larsen, et al. 1979), the Service Satisfaction Scale (SSS-30) (Attkisson and Greenfield. 1996) and the Verona Service Satisfaction Scale (VSSS-32) (Rugger, et al. 1996). Furthermore, there are also other modified tools to use in the methadone services like modified (Satisfaction with HIV/AIDS Treatment Interview Scale) SATIS instrument; a 10-item scale instrument to measure three dimensions of methadone services: "services quality and convenience", "health workers' capacity and responsiveness" and "inter-professional care", as well as "confidentially" and "responsiveness" were included in observation. Taking a long-term methadone treatment compared to 3, 6 and 12-month treatment is significantly beneficial and less positive urine drug tests, reducing commercial sex activities among drug users compared to baseline (Zhang, et al. 2013). Historically, a short methadone programme review in 2013, the following challenges were reported; inconvenient operational hours, long distance to travel for MMT patients, lengthy registration process, ongoing injecting among a significant number of patients, long induction period, and lack of confidentiality (U. Myanmar 2015). So, based on different satisfactory assessments, this study used the VSSS-MT because results of VSSS-MT measures would multi-dimensionally suggest methadone patient satisfaction with methadone treatment centres on social worker and psychologist skills, basic interventions and specific interventions respectively. Thus, methadone patients who are at least on 6-month methadone maintenance would identify the service satisfaction on methadone treatment experience in the programme were assessed with VSSS-MT tools to identify the treatment satisfaction comprehensively.

\section{Methods}




\section{Study design, respondents and location}

This study determines the treatment satisfaction situation and parameters associated with the methadone service satisfaction of patients enrolled methadone treatment in Myanmar. Methadone patients who were at least six months on treatment were recruited from all States and Regions where methadone services were provided. Sample collection sites from each State and Region were selected with stratified random sampling. A total of 210 respondents were recruited in the survey with 42 from each selected cities, Yangon, Mandalay, Lashio from Shan State, Kawlin from Saging Region and Mohnyin from Kachin State for primary data and sample collections.

\section{Inclusion and exclusion criteria}

Inclusion criteria of the survey is a) above 18 years of age, b) self-reported as a methadone user who is currently enrolled in a formal methadone programme in Myanmar, and c) must have at least a minimum of six-month methadone treatment history. The exclusion criteria is self-reported to have current psychological problems or were observed to be under serious medical conditions which could ultimately affect the study participation.

\section{Measures}

Primary data and sample data collection was done from May 2017 to July 2017 at the five selected cities. Respondents have to answer a semi-structure questionnaire to evaluate the respondent's service satisfaction on the component of methadone treatment programme with the Verona Service Satisfaction Scale for methadone-treated opioid dependent patients ( (Cobos, et al. 2002)), questionnaires of an abbreviated generic Quality of Life Scale developed through the World Health Organization (WHOQOLBREF) (WHO 2004), The Addiction Severity Index- Lite (ASI) (McLellan, et al. 1999), and Timeline Follow Back (TLFB survey) (NIDA-CTN 2014) to determine respondents drug use frequency in the last 7 days. The responses were coded with Likert's 5 point scale ( 1 for the worst satisfaction ranging to 5 : the most satisfied situation for each characteristic questions). These satisfactory responses were grouped into 3 categories of the methadone service programme clinic staff professional skills (e.g. doctor, nurse, counsellor etc.), basic intervention (instruction between visits, side-effects etc.) and specific intervention (e.g. individual rehabilitation and psychotherapy, group therapy etc) categories.

\section{Urinalysis}

Urinalysis included identification of methadone and common illicit drugs in the urine. Those respondents who consented for agreement to take part in the study were verified with methadone test kit and confirmed their participation. Further urine tests for illicit drug use status (Morphine, Cannabis, Methamphetamine, Amphetamine, and Benzodiazepine) were processed alongside with physical measurements, interview survey questionnaires to identify demographic data, reported infectious disease 
status, methadone treatment profile, their perception on methadone programme and their satisfaction level on methadone treatment.

\section{Statistical analysis}

VSSS-MT Treatment satisfaction was analysed. For identifying association of differences between categorical variables of patient characteristics with VSSS-MT Treatment satisfaction, chi-square test was done. Comparing the differences between mean scores of the interested parameters (VSSS scores) was done with t-tests. Binary logistic regression was done for identifying the predictors to the outcome "VSSS scale" at $p=0.05$ to recheck the stepwise regression output while controlling the confounding variables. With the availability of cross-sectional data, treatment satisfaction was further estimated with cox proportional hazard model especially for HIV infection as HIV status is related to dose of methadone (Tun, Vicknasingam and Singh 2018). Data analysis was done using Stata 14.0 software.

\section{Ethical Measures}

The protocol of the research proposal was interviewed and approvals were granted by the Universiti Sains Malaysia (University of Science, Malaysia) Human Ethics Committee (No. USM/ JEPeM/16080269) and Myanmar Ministry of Health and Sports, Department of Medical Research (No: Ethics/DMR/2017/057) (Research 2017). Furthermore, preparatory arrangement were made for the privacy of the individual interview session. Physical measurement and urine sample collection sample collections of the respondents in a confidential way.

\section{Results}

Demographic Characteristics

Respondents' average age is 33.3 years (ranging from 20 to 76 years). Majority of the respondents were male $98.6 \%$ and $1.4 \%$ were female. As the majority, 209 took methadone daily from the methadone dispensing sites and $1(0.48 \%)$ had take-home dose and all reported their history of opioid abuse. Majority of methadone patients are their first time of treatment for methadone 173 (83\%) and getting more than one time treatment is $35(17 \%)$ and treatment frequency of methadone ranges from 1 to 6 times. The average methadone dose is $83 \mathrm{mg}$ (with a range of $20 \mathrm{mg}$ to $300 \mathrm{mg}$ ) and their average duration on treatment is 28 months (range: 6 to 127 months). Meanwhile, almost two thirds $(63 \%, n=$ 132) had methadone dose less than or equal $80 \mathrm{mg}$ daily dose while $75(37 \%, n=76)$ had more than $80 \mathrm{mg}$ daily dose. Their average Body Mass Index (BMI) is 20.5 (range from14.0 to 33.3). More than two thirds; 159 (75.57\%) had primary through high school education and $45(21.43 \%)$ had college level while only $6(2.86 \%)$ had non-formal education. Almost half; 96 (46.38\%) were single/ divorced and 84 (40.58\%) were married while 27 (13.04\%) were separated. Their historic working status within 3 years showed that the majority; 192 (93.43\%) had recent jobs (previous 3-year period) and $18(8.57 \%)$ were in no-job categories (including disabled, students). However, 28 (13.46\%) had received their income from the 
drug negotiation within 30 days. Twenty-nine (13.81\%) were working as outreach workers or peereducators for drug users. The VSSS scale was mentioned based on responses to each question in Table 1. 
Table 1

Table shows VSSS-MT Treatment satisfaction scale among respondents

\begin{tabular}{|c|c|c|c|}
\hline Variable & $\begin{array}{l}\text { Frequency } \\
\text { (n and \%) }\end{array}$ & Mean (SD) & Range \\
\hline $\begin{array}{l}\text { Verona Service Satisfaction Scale for Methadone-Treatment } \\
\text { (VSSS-MT) scale }\end{array}$ & $\begin{array}{l}209 \\
(100 \%)\end{array}$ & $\begin{array}{l}100.22 \\
(14.19)\end{array}$ & $\begin{array}{l}58- \\
131\end{array}$ \\
\hline Not much satisfied & $23(11 \%)$ & & \\
\hline Much satisfied & $186(89 \%)$ & & \\
\hline \multicolumn{4}{|l|}{ VSSS Item Categories } \\
\hline Professional Skills Items & 209 & $3.89(0.64)$ & $1.5-5$ \\
\hline Basic Interventions Items & 209 & $3.83(0.54)$ & $2.3-5$ \\
\hline Specific Interventions Items & 209 & $3.42(0.68)$ & $\begin{array}{l}1.5- \\
4.9\end{array}$ \\
\hline \multicolumn{4}{|l|}{ VSSS Items Description } \\
\hline 1. Helping patient deal with problem & 209 & $3.77(0.96)$ & \\
\hline 2. Doctors' ability to listen & 208 & $3.97(0.83)$ & \\
\hline 3. Psychologists' ability to listen & 206 & $3.99(0.86)$ & \\
\hline 4. Doctors' manner & 208 & $3.92(0.84)$ & \\
\hline 5. Psychologists' manner & 204 & $4.02(0.77)$ & \\
\hline 6. Referring to other specialists & 201 & $3.76(0.87)$ & \\
\hline 7. Overall satisfaction & 208 & $4.22(0.76)$ & \\
\hline 8. Nurses' manner & 209 & $3.91(0.84)$ & \\
\hline 9. Social workers' manner & 205 & $3.73(1.00)$ & \\
\hline 10. Improving relationship between patient and relatives & 208 & $4.00(0.84)$ & \\
\hline 11. Helping family members to understand patient's problems & 209 & $4.01(0.81)$ & \\
\hline 12. Nurses' knowledge of patient's medical history & 209 & $3.78(0.94)$ & \\
\hline 13. Information on addiction & 209 & $3.72(0.93)$ & \\
\hline 14. Helping patient in relationships outside the family & 209 & $3.44(1.04)$ & \\
\hline 15. Instructions between visits & 209 & $3.79(0.85)$ & \\
\hline 16. Helping patient to look after himself & 209 & $3.98(0.77)$ & \\
\hline 17. Nurses' ability to listen & 208 & $3.83(0.84)$ & \\
\hline
\end{tabular}




\begin{tabular}{|lll|}
\hline Variable & $\begin{array}{l}\text { Frequency } \\
\text { (n and \%) }\end{array}$ & Mean (SD) \\
\hline 18. Social workers' ability to listen & 209 & $3.75(0.92)$ \\
\hline 19. Help received for methadone side effects & 207 & $3.88(0.85)$ \\
\hline 20. Individual rehabilitation & 209 & $3.64(1.07)$ \\
\hline 21. Individual psychotherapy & 209 & $3.67(1.05)$ \\
\hline 22. Family therapy & 208 & $4.19(0.81)$ \\
\hline 23. Activities organised by centre & 209 & $3.82(0.97)$ \\
\hline 24. Group psychotherapy & 209 & $3.33(1.06)$ \\
\hline 25. Sheltered work & 208 & $3.03(1.23)$ \\
\hline 26. Help by the centre at home & 204 & $2.51(1.27)$ \\
\hline 27. Help to join in activities separate from the centre & 209 & $3.16(1.17)$ \\
\hline
\end{tabular}

Treatment satisfaction rating differed with study sites, lower in the big cities (Yangon, Mandalay) and higher in the small cities (Kawlin, Lashio and Mohnyin). Satisfaction with methadone service (VSSS-MT score) was reported as 100 for average and ranging from 58 to 131 whereas over 80 as "much satisfaction"; rated 3 above Likert scale of 5 for all questionnaires. A total of $88.57 \%(n=186)$ were "much satisfied" with methadone service. However, VSSS-MT score rated professional skill items (doctor, nurse, counsellor and worker) as 3.89 out of 5 , basic intervention items as 3.83 and specific intervention items as 3.42 . Those on high methadone dose with more than $80 \mathrm{mg}$ gave higher satisfaction rating than low dose personnel $(p=0.0276)$.

Differences of VSSS scales with respondents' characteristics

There are VSSS domain scale differences with the characteristics of methadone patients as described in Table 2. 
Table 2

Table shows total VSSS-MT scale differences by the characteristics of patients

\begin{tabular}{|c|c|c|c|c|}
\hline Respondent characters & Sub groups & $\begin{array}{l}\text { Number } \\
\text { (n) }\end{array}$ & $\begin{array}{l}\text { Total VSSS- } \\
\text { MT score }\end{array}$ & $\mathrm{p}$ value \\
\hline \multirow[t]{2}{*}{ Methadone dose categories } & less than or equal $80 \mathrm{mg}$ & 132 & 99 & $0.0276^{\star *}$ \\
\hline & more than $80 \mathrm{mg}$ & 76 & 103 & \\
\hline \multirow[t]{2}{*}{ Methadone duration } & \multirow{2}{*}{$\begin{array}{l}\text { less than or equal } 2.4 \text { years } \\
\text { more than } 2.4 \text { years }\end{array}$} & 120 & 101 & 0.4755 \\
\hline & & 89 & 99 & \\
\hline \multirow[t]{2}{*}{ Methadone treat time } & First time treatment & 173 & 101 & $0.0120 * *$ \\
\hline & More than first time & 35 & 95 & \\
\hline \multirow[t]{2}{*}{ - less than or equal $80 \mathrm{mg}$} & First time treatment & 109 & 100 & $0.0091^{\star \star}$ \\
\hline & More than first time & 22 & 92 & \\
\hline \multirow[t]{2}{*}{ - more than $80 \mathrm{mg}$} & First time treatment & 63 & 104 & 0.4167 \\
\hline & More than first time & 13 & 100 & \\
\hline \multirow{2}{*}{$\begin{array}{l}\text { - less than or equal } 2.4 \\
\text { years }\end{array}$} & First time treatment & 95 & 103 & 0.0052 \\
\hline & More than first time & 24 & 94 & \\
\hline \multirow[t]{2}{*}{ - more than 2.4 years } & First time treatment & 78 & 100 & 0.6067 \\
\hline & More than first time & 11 & 97 & \\
\hline \multirow[t]{2}{*}{ HIV status (HIV) } & Not infected & 126 & 99 & 0.1351 \\
\hline & Infected & 74 & 102 & \\
\hline \multirow[t]{2}{*}{ Hepatitis C status (HCV) } & Not infected & 77 & 103 & $0.0452^{\star *}$ \\
\hline & Infected & 71 & 99 & \\
\hline \multirow[t]{2}{*}{ Hepatitis B status (HBV) } & Not infected & 166 & 101 & 0.8754 \\
\hline & Infected & 15 & 102 & \\
\hline \multirow{2}{*}{$\begin{array}{l}\text { Tuberculosis (TB) treatment } \\
\text { history }\end{array}$} & Not treated & 147 & 101 & 0.9021 \\
\hline & treated & 54 & 101 & \\
\hline \multirow{2}{*}{$\begin{array}{l}\text { Sexually Transmitted } \\
\text { infection (STI) history }\end{array}$} & Not infected & 164 & 100 & 0.7577 \\
\hline & Infected & 45 & 101 & \\
\hline \multirow[t]{2}{*}{ Age } & Younger and equal 35 years & 128 & 101 & 0.4433 \\
\hline & Older than 35 years & 81 & 99 & \\
\hline
\end{tabular}




\begin{tabular}{|c|c|c|c|c|}
\hline Respondent characters & Sub groups & $\begin{array}{l}\text { Number } \\
\text { (n) }\end{array}$ & $\begin{array}{l}\text { Total VSSS- } \\
\text { MT score }\end{array}$ & $p$ value \\
\hline \multirow[t]{2}{*}{ Body Mass Index (BMI) } & Less than mean BMI (20.5) & 122 & 100 & 0.9412 \\
\hline & More than mean BMI & 84 & 100 & \\
\hline \multirow{2}{*}{$\begin{array}{l}\text { Currently on antiretroviral } \\
\text { therapy (ART) }\end{array}$} & No & 141 & 99 & 0.0938 \\
\hline & On treatment & 68 & 103 & \\
\hline \multirow[t]{2}{*}{ Education } & Up to primary & 48 & 105 & $0.0110^{\star \star}$ \\
\hline & More than primary & 161 & 99 & \\
\hline \multirow[t]{2}{*}{ Recent work } & Unemployed & 24 & 97 & 0.1926 \\
\hline & Employed & 182 & 101 & \\
\hline \multirow[t]{2}{*}{ Current Peer/ Outreach } & No & 180 & 101 & 0.4528 \\
\hline & Peer/outreach & 29 & 98 & \\
\hline \multirow[t]{2}{*}{ ASI for Employment } & Low score & 102 & 99 & 0.4711 \\
\hline & High score & 104 & 101 & \\
\hline \multirow[t]{2}{*}{ ASI for Alcohol Use } & Low score & 28 & 106 & 0.2600 \\
\hline & High score & 36 & 102 & \\
\hline \multirow[t]{2}{*}{ ASI for Drug Use } & Low score & 162 & 101 & 0.1604 \\
\hline & High score & 47 & 98 & \\
\hline \multirow[t]{2}{*}{ ASI for Legal Status } & Low score & 14 & 102 & 0.1590 \\
\hline & High score & 14 & 94 & \\
\hline \multirow{2}{*}{$\begin{array}{l}\text { ASI for Family/ Social } \\
\text { Status }\end{array}$} & Low score & 139 & 101 & 0.3306 \\
\hline & High score & 70 & 99 & \\
\hline \multirow[t]{2}{*}{ Marital status } & Currently married & 84 & 99 & 0.1568 \\
\hline & Single/separated & 122 & 101 & \\
\hline \multirow[t]{2}{*}{ Income } & Lower (than average) & 131 & 100 & 0.4542 \\
\hline & Higher & 77 & 101 & \\
\hline \multirow{2}{*}{$\begin{array}{l}\text { Current marital status } \\
\text { satisfaction }\end{array}$} & Not satisfied & 20 & 97 & 0.2375 \\
\hline & Satisfied & 189 & 101 & \\
\hline
\end{tabular}

Independent t-test $\mathrm{p}$ value: ** significance $<0.05$, $* * *$ significance $<0.001$ 


\begin{tabular}{|c|c|c|c|c|}
\hline Respondent characters & Sub groups & $\begin{array}{l}\text { Number } \\
(n)\end{array}$ & $\begin{array}{l}\text { Total VSSS- } \\
\text { MT score }\end{array}$ & $p$ value \\
\hline \multirow{2}{*}{$\begin{array}{l}\text { WHO Quality of life (QOL) } \\
\text { total score }\end{array}$} & Low & 88 & 94 & $0.0000 * * *$ \\
\hline & High & 121 & 105 & \\
\hline \multirow[t]{2}{*}{ Physical QOL score } & Low & 53 & 89 & $0.0000 * * *$ \\
\hline & High & 156 & 104 & \\
\hline \multirow[t]{2}{*}{ Psychological QOL score } & Low & 41 & 91 & $0.0000 * * *$ \\
\hline & High & 168 & 102 & \\
\hline \multirow[t]{2}{*}{ Social QOL score } & Low & 71 & 95 & $0.0001 * * *$ \\
\hline & High & 138 & 103 & \\
\hline \multirow[t]{2}{*}{ Environmental QOL score } & Low & 54 & 91 & $0.0000 * \star *$ \\
\hline & High & 155 & 103 & \\
\hline \multirow{2}{*}{$\begin{array}{l}\text { Current leisure status } \\
\text { satisfaction }\end{array}$} & Not satisfied & 29 & 92 & $0.0012^{\star \star}$ \\
\hline & Satisfied & 180 & 101 & \\
\hline \multirow{2}{*}{$\begin{array}{l}\text { - Current leisure status with } \\
\text { family }\end{array}$} & Not satisfied & 119 & 100 & 0.8200 \\
\hline & Satisfied & 90 & 100 & \\
\hline \multirow{2}{*}{$\begin{array}{l}\text { - Current leisure status with } \\
\text { friend }\end{array}$} & Not satisfied & 135 & 100 & 0.3354 \\
\hline & Satisfied & 74 & 102 & \\
\hline \multirow{2}{*}{$\begin{array}{l}\text { - Current leisure status } \\
\text { alone }\end{array}$} & Not satisfied & 159 & 101 & 0.1123 \\
\hline & Satisfied & 50 & 97 & \\
\hline \multicolumn{5}{|l|}{$\begin{array}{l}\text { Abuse encountered within } \\
30 \text { days }\end{array}$} \\
\hline \multirow[t]{2}{*}{ - Psychological abuse } & Not experienced & 183 & 100 & 0.7474 \\
\hline & Experienced & 22 & 101 & \\
\hline \multirow[t]{2}{*}{ - Physical abuse } & Not experienced & 203 & 100 & \\
\hline & Experienced & 1 & 102 & \\
\hline \multirow[t]{2}{*}{ - Sexual abuse } & Not experienced & 204 & 100 & \\
\hline & Experienced & 1 & 111 & \\
\hline
\end{tabular}

Independent t-test $\mathrm{p}$ value: ** significance $<0.05$, ${ }^{* * *}$ significance $<0.001$ 


\begin{tabular}{|c|c|c|c|c|}
\hline Respondent characters & Sub groups & $\begin{array}{l}\text { Number } \\
(n)\end{array}$ & $\begin{array}{l}\text { Total VSSS- } \\
\text { MT score }\end{array}$ & $p$ value \\
\hline \multirow[t]{2}{*}{ - Urine Morphine } & Absent & 93 & 101 & 0.7137 \\
\hline & Present & 116 & 100 & \\
\hline \multirow{2}{*}{$\begin{array}{l}\text { - Urine } \\
\text { Tetrahydrocannabinol } \\
\text { (THC) }\end{array}$} & Absent & 185 & 100 & 0.5802 \\
\hline & Present & 24 & 99 & \\
\hline \multirow[t]{2}{*}{ - Urine Methamphetamine } & Absent & 158 & 101 & 0.2034 \\
\hline & Present & 51 & 98 & \\
\hline \multirow[t]{2}{*}{ - Urine Amphetamine } & Absent & 191 & 100 & 0.9167 \\
\hline & Present & 18 & 101 & \\
\hline \multirow[t]{2}{*}{ - Urine Benzodiazepine } & Absent & 137 & 101 & 0.3853 \\
\hline & Present & 72 & 99 & \\
\hline \multirow{2}{*}{$\begin{array}{l}\text { Last heroin injection within } \\
30 \text { days }\end{array}$} & No & 93 & 102 & $0.0483^{\star *}$ \\
\hline & Yes & 115 & 98 & \\
\hline \multirow[t]{2}{*}{ Frequency of injection } & No or few inj: $($ mean $=7)$ & 96 & 102 & $0.0373^{\star *}$ \\
\hline & Higher & 112 & 98 & \\
\hline \multirow{2}{*}{$\begin{array}{l}\text { Needle sharing within } 30 \\
\text { days }\end{array}$} & Not shared & 99 & 99 & 0.7169 \\
\hline & Shared & 4 & 102 & \\
\hline \multirow{2}{*}{$\begin{array}{l}\text { Life time sharing of needle } \\
\text { and syringes }\end{array}$} & Not shared & 106 & 99 & 0.1452 \\
\hline & Shared & 102 & 102 & \\
\hline
\end{tabular}

Among the different characteristics of the respondents, higher quality of life on physical, psychological, social and environmental categories, respondents who satisfied on current marital status and current leisure status, respondents who were on alcohol were associated with higher treatment satisfaction on methadone, over 80 as "much satisfaction"; $(p<0.05)$ as mentioned in Graph 1.

Stepwise regression analysis

After considering significant associated characteristics in the model affecting to the VSSS service satisfaction scale, stepwise binary logistic regression was done among the significant parameters in the model to identify final predictors to the outcome group for "VSSS service satisfaction scale" in Table 3. 
Table 3

Table shows correlates of VSSS scale from stepwise regression

\begin{tabular}{|llc|}
\hline Variable & Adjusted Odds Ratio (aOR) $(95 \% \mathrm{Cl})$ & p value \\
\hline Alcohol & $5.57(1.2,25.88)$ & $0.029 * \star$ \\
\hline Physical quality of life (QOL) score & $11.87(4.29,32.84)$ & $0.000^{\star \star *}$ \\
\hline Stepwise binary logistic regression, p value: $* *$ significance $<0.05, * \star \star$ significance $<0.001$ \\
\hline
\end{tabular}

Retention in logistic regression was predicted the associated characteristics which impacted on the VSSS service satisfaction scale.

In the analysis of binary logistic regression, this analysis estimated the association of independent variables to the outcome variable of VSSS service satisfaction scale category of the methadone patients after controlling the potential confounding variables for adjustment. Alcohol alone had 6 times (aOR 5.57, $95 \% \mathrm{Cl} ; 1.20-25.88, \mathrm{p}=0.029$ ) while respondents in good physical health (with higher score in physical quality of life) had 12 times (aOR $11.87,95 \% \mathrm{Cl} ; 4.29-32.84, \mathrm{P}=0.000$ ) in contributing to the high VSSS service satisfaction scale. When checking for the multi collinearity, mean variance inflation factor (vif) was 1.61 and none of the variable has more than 10 . The regression model alpha ratio is set at 0.05 .

Reported Infection status of the patients

Among the methadone respondents, just above one-third $(36.5 \%, \mathrm{n}=76)$ received high-dose (more than $80 \mathrm{mg} /$ day) and the rest $63.5 \%(\mathrm{n}=132)$ received low-dose on methadone (less than $80 \mathrm{mg} / \mathrm{day})$. Almost half of the respondents reported hepatitis $C$ virus infection (HCV) $(47 \%, n=71 / 148), 37 \%$ reported Human Immunodeficiency Virus (HIV) infection $(n=74 / 200)$, while $16 \%(n=34)$ reported HIV and HCV coinfection. Forty-five (21.53\%) reported that they experienced sexually transmitted infections and Hepatitis B infection by 15 (8.29\%). Among HIV infected respondents, 68 (92\%) were on antiretroviral therapy (ART) and their average ART duration was 30-months (range: 1 to 132 months). In Myanmar, the most commonly prescribed antiretroviral regimen is the combination of tenofovir, emtricitabine and efavirenz which account for $86 \%$ which requires a significant methadone dose adjustment. More than $80 \mathrm{mg}$ of high methadone dose is associated with taking antiretroviral therapy $(p=0.039)$.

Treatment satisfaction by methadone dose and infection status

Based on the available cross-sectional data, treatment satisfaction was trying to estimate with cox proportional hazard model assuming the model of in the way of cohort data. Based on estimated model on HIV infection, treatment satisfaction was 2 times higher among HIV negative compared to HIV positive patients after controlling the methadone dose variable (IRR $=0.49, p=0.000)$. Similarly for co-infection status (HIV and HCV), satisfaction was 1.7 times higher among non-co-infected patients than co-infected patients $(\mathrm{IRR}=0.59, \mathrm{p}=0.000)$. 
Higher rate of satisfaction incidence was $1.49 \%$ among HIV negative respondents and $0.72 \%$ among HIV positive respondents after adjusting for methadone dose $(p=0.000)$. Higher dose was associated with increased satisfaction scales $(p=0.037)$ in HIV negative respondents.

Difference of higher satisfaction incidence was showed in $1.2 \%$ among non-co-infected patients and $0.71 \%$ among co-infected patients with adjusted doses. Co-infected patients were less likely to get satisfaction compared to non-co-infected patients $(p=0.000)$.

\section{Discussion}

This study elaborates factors associated with methadone treatment satisfaction VSSS scale. Besides basic methadone services and staff interaction of the methadone service providers, some of the factors that significantly influences on satisfaction of specific service provision of methadone are recent heroin injections, respondents taking benzodiazepine, those infected with HCV, those who had higher addiction severity index on alcohol and family/ social status, etc. So, it is highly important that ancillary services of methadone programme; counselling, medical services, psycho-social services, and psychiatric care will enhance the outcome for methadone treatment. It is also aligned with treatment satisfaction is higher among methadone clinics with other healthcare services than methadone service alone (Tran, et al. 2015). Treatment progression (estimate $=0.227, \mathrm{SE}=0.019, \mathrm{p}<0.01$ ) and counselling rapports (estimate $=0.229, \mathrm{SE}=0.016, \mathrm{p}<0.01)$ had positive associations with treatment satisfaction ( $\mathrm{Li}$, et al. 2017). Meanwhile, responses from Malaysian clients raised that dosing area; waiting area and staff shortage were most desired changes from the methadone clients (Aziz and Chong 2015). Another analysis result from Spain, multiple linear regression showed methadone satisfaction depended on methadone dispensing hour, influence on methadone dose change, number of patients per centre, perceived frequency of receiving information about methadone dose changes, and social dysfunction subscale of GHQ-28 (General Health Questionnaire-28; lower social dysfunction was related to higher satisfaction) ( $p$ $<0.05$ ) (Trujols, et al. 2012).

The result of stepwise binary logistic regression showed alcohol use and physical health has significantly associated with treatment satisfaction. So, alcohol usage along with methadone is also an important factor to consider the drug rehabilitation programme and measures. Higher satisfaction was also shown when methadone treatment is provided with other associated healthcare services than treating only with methadone. The satisfaction results from Vietnam reflected that comprehensive care clinics services with physical, psychological and HIV related care are important in the service provision. Meanwhile, treatment satisfaction for "staff category" of methadone treatment was high in Myanmar and it was also seen in Vietnamese study of Tran study which also showed the highest in "capacity of health workers \& responsiveness" with lowest proportion in "Quality" (49.0\%) and "Convenience" (51.1\%) (Tran, et al. 2015).

This study also has a few limitations as the respondents were recruited who are taking methadone currently and those who are not satisfied with the services can be omitted unintentionally from the 
recruitment process. Based on the cross-sectional data, estimation of the service satisfaction among patients with infection status has methodology limitation due to the data availability other than the cohort nature. Furthermore, due to the sample size limitation, it is expected that limitations in the conclusion for respondents with specific characteristics. As the respondents are the current patients taking on methadone, the patients can be under Hawthorn's effect and can avoid the unexpected risk of answering pessimistic views although there was a proper explanation for ensuring their confidentiality in answering their opinion.

There were other factors to consider for evaluation of methadone services like early drop-outs and refusals to participate, which could contribute uncertainty of the results obtained and a threat to the internal validity and generalizability of such results.

To ensure the reflective answer for methadone patients, those who were retained at least six-month in the programme were set as a criterion for inclusion in the survey. Meanwhile, in terms of drug efficacy in retention of the patients compared to other opioid substitution, it was reported in the Cochrane review that methadone maintenance is superior in retaining patients in opioid substitution therapy compared to buprenorphine at low fixed dose (Mattick, et al. 2014).

Respondents on methadone were generally satisfied with the services they received. It was clear in the results that specific intervention works were necessary to expand and improved for treatment satisfaction. As the specific intervention works focuses on individual and group counselling, family support, centre supports at home, the methadone intervention is more effective if it integrated with individual and/or group counselling, employment or family services (Opioid Addiction 2018). This finding was higher than a study result from Spain and average total score was $3.4(S D=0.6)$; with Basic Interventions mean scores $3.5(S D=0.7)$, Specific Interventions scores $3.1(S D=0.8)$, Social Worker Skills $3.5(\mathrm{SD}=1.0)$, and Psychologist Skills $3.6(\mathrm{SD}=0.9)$ (Trujols, et al. 2012).

\section{Conclusion}

Pharmacological response from urine drug results also encouraged that optimal dose of methadone based on the clinical profile of patient was also effective in reducing the illicit opioid drug injection among methadone patients. Furthermore, community based approach with the individual rehabilitation with family support, individualized care from the treatment centres are recommended in delivering effective methadone treatment and prevention of further illicit drug use and infections for strengthening of specific intervention category of methadone treatment. Treatment of the people who inject drugs (PWID) and their family members at their place are also important for expansion among harm reduction organizations and early access of interventions will prevent further infections and get the treatment earlier in a social integrated approach.

\section{Abbreviations}


aOR: Adjusted Odds Ratio

ART: Antiretroviral therapy

ASI: Addiction Severity Index

BMI: Body Mass Index

DDTRU: Drug Dependency Treatment and Research Unit

HCV: Hepatitis C Virus

HIV: Human Immunodeficiency Virus

IRR: Incidence Rate Ratio

MMT: Methadone Maintenance Treatment

PWID: People Who Inject Drugs

SD: Standard Deviation

VSSS-MT: The Verona Service Satisfaction Scale for Methadone-Treatment

WHO: World Health Organization

WHOQOL-BREF: generic Quality of Life Scale developed through the World Health Organization

\section{Declarations}

\section{Ethical Approval and Consent to participate}

This research approval was granted from the Human Ethics Committee of the Universiti Sains Malaysia (No:USM/ JEPeM/16080269) (University of Science, Malaysia) and Department of Medical Research (No: Ethics/DMR/2017/057), Ministry of Health and Sports, (Research 2017).

\section{Consent for publication}

All authors read and approved final manuscript submission. All authors agree to publish this prepared manuscript and no other submission of this manuscript to other journal.

\section{Competing Interest}

All authors declare that there is no competing interest. 


\section{Funding}

Authors declared that the research and publication of their article was self-funded for academic purpose.

\section{Authors' Contributions}

Sun Tun contributed in designing, implementation, analysis and wrote the manuscript. B. Vicknasingam and Darshan Singh contributed in designing, analysis and contributed in this manuscript.

\section{Data Availability}

The [.dta] data used to support the findings of this study are available from the corresponding author upon the approval of the Centre for Drug Research.

\section{Acknowledgments}

The authors would like to thank to all survey respondents and Dr. Nanda Myo Aung Wan, Drug Dependency Treatment and Research Unit (DDTRU) Programme Manager in Myanmar who supported in proposal development. Further appreciation goes to Dr. Ohnmar Thaung, U Thet Swe, Dr. Phyo Myat, Dr. Nay Lin, Dr. Myo Min Min and harm reduction organizations in Myanmar (Myanmar Anti-Narcotic Association, Burnet Institute, Asian Harm Reduction Network) for supporting survey data collection.

\section{References}

1. "The Client Satisfaction Questionnaire (CSQ) Scales." In Outcome Assessment in Clinical Practice, by C. Clifford Attkisson, \& T. K. Greenfield., edited by L. L. Sederer , \& B. Dickey. Baltimore, MD: Williams \& Wilkins, 1996.

2. Aziz, Zoriah, and Nyuk Jet Chong. "A Satisfaction Survey of Opioid-Dependent Patients with Methadone Maintenance Treatment." Journal of Substance Abuse Treatment (Elsevier) 53 (Jun 2015): 47-51.

3. Chou, Ying-Chun, Shu-Fang Shih, Wei-Der Tsai, Chiang-shan R Li, Ke Xu, and Tony Szu-Hsien Lee. "Improvement of quality of life in methadone treatment patients in northern Taiwan: a follow-up study." BMC Psychiatry (Bio Med Central) 13, no. 190 (2013).

4. Cobos, Jose' Pe'rez de los, et al. "Development and psychometric properties of the Verona Service Satisfaction Scale for methadone-treated opioid-dependent patients (VSSS-MT)." Drug and Alcohol Dependence (Elsevier) 68, no. 2 (Oct 2002): 209-214.

5. DDTRU. National Drug Abuse Prevention and Control Programme. Yangon: DDTRU, 2015. 
6. Fei, Joni Teoh Bing, Anne Yee, Mohamad Hussain Bin Habil, and Mahmoud Danaee. "Effectiveness of Methadone Maintenance Therapy and Improvement in Quality of Life Following a Decade of Implementation." Journal of Substance Abuse Treatment, July 2016: 50-56.

7. Larsen, Daniel L., C. Clifford Attkisson, William A. Hargreaves, and Tuan D. Nguyen. "Assessment of client/patient satisfaction: Development of a general scale." Evaluation and Program Planning (Elsevier) 2, no. 3 (1979): 197-207.

8. Li, Li, W. Scott Comulada, Chunqing Lin, Julie Hsieh, Sitong Luo, and Zunyou Wu. "Factors related to client satisfaction with methadone maintenance treatment in China." Journal of Substance Abuse Treatment 77 (Jun 2017): 201-206.

9. Mattick, Richard, Courtney Breen, Jo Kimber, and Marina Davoli. "Buprenorphine maintenance versus placebo or methadone maintenance for opioid dependence." Cochrane Database of Systematic Reviews, no. 2 (Feb 2014).

10. McLellan, Thomas, John Cacciola, Deni Carise, and Thomas H. Coyne. "Addiction Severity Index Lite CF." 1999.

11. methadone, WHO. Pharmacotherapy with methadone. 2014.

12. Myanmar, The Global Fund Programme in. The Global Fund Programme in Myanmar. Sep 23, 2020. https://pr-myanmar.org/en/disease/hiv.

13. Myanmar, UNAIDS. Situational Analysis on Drug Use, HIV and the Response in Myanmar: Looking Forward. Yangon: UNAIDS, 2015.

14. NIDA-CTN. Instrument: Timeline Followback Method Assessment. 2014. https://cde.drugabuse.gov/sites/nida_cde/files/TimeLineFollowBack_2014Mar24.pdf.

15. "Opioid Addiction." In Principles of Drug Addiction Treatment: A Research-Based Guide (Third Edition). 2018.

16. Research, Department of Medical. http://www.ercdmrlm.org . April 2017. http://www.ercdmrlm.org/pdf/2017_Certificate_List.pdf.

17. Rugger, Mirella , Dallagnola Rosa, Giulia Bisoffi, and Tom Greenfield. "Factor analysis of the Verona Service Satisfaction Scale-82 and development of reduced version." International Journal of Methods in Psychiatric Research 6, no. 1 (Apr 1996): 23-38.

18. Tran, Bach Xuan, Long Hoang Nguyen, Huong Thu Thi Phan, and Carl A. Latkin. "Patient Satisfaction with Methadone Maintenance Treatment in Vietnam: A Comparison of Different Integrative-Service Delivery Models." PLOS One (PLoS One) 10, no. 11 (Nov 2015): e0142644.

19. Trujols, Joan, Inmaculada Garijo, Núria Si nol, Juan del Pozo, Maria J. Portella, and José Pérez de los Cobos. "Patient satisfaction with methadone maintenance treatment: The relevance of participation in treatment and social functioning." Drug and Alcohol Dependence(Elsevier) 123 (2012): 41-47.

20. Tun, Sun, B. Vicknasingam, and Darshan Singh. "Increased methadone dose reduces illicit drug injection among HIV negative methadone clients in Myanmar." Journal of the International AIDS Society 21, no. 56 (Jul 2018): e25148. 
21. UNODC. World Drug Report 2020. UNODC, 2020.

22. WHO. "The World Health Organization Quality of Life (WHOQOL)-BREF." 2004.

23. YI, Hser, et al. "Long-term outcomes after randomization to buprenorphine/naloxone versus methadone in a multi-site trial." Addiction 111, no. 4 (April 2016): 695-705.

24. Zhang, Lei, et al. "Methadone Maintenance Treatment Participant Retention and Behavioural Effectiveness in China: A Systematic Review and Meta-Analysis." PLOSone (PLOSone), Jul 2013.

\section{Figures}

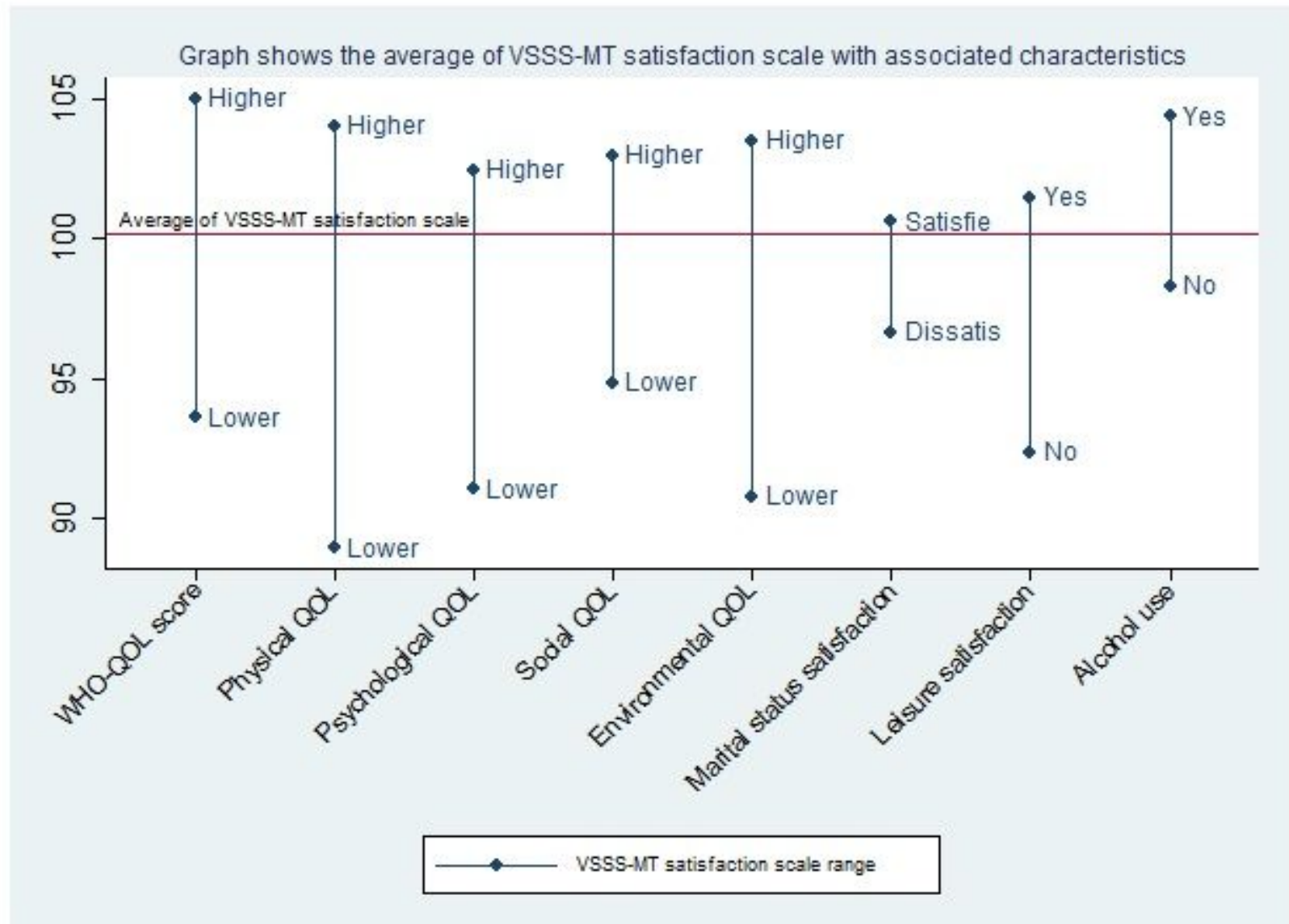

\section{Figure 1}

Graph shows the average of VSSS-MT satisfaction scale with associated characteristics 